\title{
Los uiri Dei en el De spiritalis de Avito de Vienne y en los Dialogi de Gregorio Magno ${ }^{1}$
}

\author{
Marcelo Aguirre Durán \\ UNIVERSIDAD DE LOS ANDES (CHILE) \\ maguirre@uandes.cl
}

El estudio de los Padres de la Iglesia se puede constituir en una fuente de inagotable acercamiento a lo que en nuestra época se conoce como la historia social, historia del pensamiento o, de modo más general aún, como historia de las mentalidades. Junto a ello, el acercamiento a algunas de las principales obras patrísticas, analizadas a partir de una aproximación desde la disciplina histórica, permite una comprensión en cierto modo más acabada de lo que conocemos como la Antigüedad tardía y la alta Edad Media, y viene a ser un reflejo de la vida y el mundo de los siglos V y VI.

Los acontecimientos que marcaron el devenir histórico de lo que hoy conocemos como la tardo-antigüedad son bien conocidos. Junto a las invasiones, la crisis interna del Imperio y la desestructuración de las instituciones tradicionales se acrecentaban a tal punto que cada vez se tornaba más real la posibilidad de creer que el fin del mundo estaba próximo. Sin embargo, este discurso escatológico, no pocas veces retomado, debería ser comprendido a partir del marco dado por una concepción cristiana de la historia, concepción en la que la teleología se constituye, necesariamente, en la meta de la historia en tanto que fin del tiempo y espera de la segunda venida de Cristo. La idea de decadencia, entonces, no se debería entender a partir de nuestras categorías contemporáneas, y no respondería solo a un fenómeno particular como lo fue la transformación del mundo romano.

Algunas décadas atrás el profesor H.-I. Marrou afirmaba que la mentalidad propia de la Roma heredada por el cristianismo contenía, en sus

\footnotetext{
1 Este artículo forma parte del proyecto de investigación FONDECYT nº 11110194.
} 
raíces mismas, una noción profunda del fin del mundo que, a su vez, le proporcionó la continuidad con el pasado en tanto que decadencia de este último ${ }^{2}$. Esta idea concebida como un déclin inévitable ${ }^{3}$, comúnmente afincada en el pensamiento de la época, habría permanecido en el concepto de la historia cristiana y habría mutado a partir de la virtud de la esperanza, virtud teologal que se constituye en articuladora del tiempo y de la historia. De este modo, los tempora christiana habrían permitido la evocación de un futuro esperanzador, despojado de las certezas terrenales y con una única orientación escatológica que les daría su sentido.

Con la aparición del cristianismo y la posterior conversión del Imperio, los autores cristianos adoptaron un particular interés por la reflexión histórica y, a través de los distintos géneros literarios y de la visión providencialista de la historia, hicieron posible la descripción y análisis de todos los acontecimientos del mundo ordenados en clave teológica. Asimismo, en esta visión cristiana de un Dios Providente y Regidor del mundo, la naturaleza caída del hombre y la acción del pecado en ella constituyen el punto axial de la infidelidad humana.

Es así como, dentro de este contexto y con el amplio repertorio de escritores latinos de los siglos V y VI, las figuras de Avito de Vienne y Gregorio Magno resultan particularmente ilustradoras, tanto por el sentido pastoral de sus obras como por la profundidad espiritual de ellas. En estos dos autores se conjugarían, según nuestro parecer, un par de elementos que se podrían considerar como fundamentales al momento de intentar un análisis de la visión cristiana de la historia de los últimos siglos de la Antigüedad: a) ambos responden a una formación de una élite intelectual, aunque en dos ámbitos geográficos y temporales distintos (Italia y Galia); b) si bien ambos pensadores no son historiadores, sí escribieron relatos que consideramos se podrían entender dentro de la dinámica de la historia salutis, pues proponen a modelos de hombres virtuosos como los verdaderos protagonistas de la historia.

Sin permanecer ajenos a las preocupaciones de sus días, tanto Avito como Gregorio ponen de manifiesto un particular interés por la historia,

2 H.-I. Marrou, "La fin du monde antique vu par les contemporaines", en G. Suffert y otros (eds.), Les terreurs de l'an 2000 (Actes du colloque international de Jouy-en-Josas, 27-30 septembre 1975) (Hachette, París 1976) 13-15.

3 H.-I. Marrou, "La fin du monde antique...., 13. 
por el sentido del devenir humano y por el futuro aparentemente catastrófico, el que iba adquiriendo una connotación hasta entonces probablemente impensable ${ }^{4}$. No en vano es posible afirmar que la reflexión histórico-teológica agustiniana, por ejemplo, es el resultado de una reflexión nacida en una época de profunda crisis, marcada por el esfuerzo intelectual de la patrística ${ }^{5}$ y perpetuada a través de los textos y de sus autores.

Dentro de esta perspectiva de la historia salutis proponemos, como objeto de estudio, dos obras que vienen a ser un valioso aporte como fuente histórica para un acercamiento a la continuidad de la cosmovisión del cristiano de los siglos $\mathrm{V}_{\mathrm{y} \mathrm{VI}}{ }^{6}$. En este sentido, y tal como lo hace notar $\mathrm{H}$. Inglebert, las obras estrictamente históricas son una minoría por estos años ${ }^{7}$, pero aquellas que han sido escritas con fines pastorales o pedagógicos no dejan de prestar valioso testimonio. En ellas se hace posible el análisis histórico a partir de la tipología de los arquetipos del uir iustus, el papel de la Providencia, así como la acción del cristiano en la comprensión y dominio del mundo. Unido a lo anterior, la cuestión del pecado original se torna un punto de especial interés para la comprensión histórica y providencialista del mundo.

El problema de la tipología ha sido ampliamente tratado por diferentes autores, pues constituye uno de los aspectos fundamentales del estudio bíblico y hagiográfico ${ }^{8}$. Esta es, además, un recurso literario ex-

4 Cf. E. Mitre, "Roma y el fin del mundo antiguo desde la Edad Media”, en G. Bravo (ed.), La caída del Imperio Romano y la génesis de Europa (Editorial Complutense, Madrid 2001).

5 Cf. H.-I. Marrou, L'Église de l'Antiquité tardive (303-604) (Le Seuil, París 1985) 218-234.

6 U. Moricca, Storia della letteratura latina cristiana, vol. III, parte II (Società editrice internazionale, Turín 1934) 1703.

7 H. Inglebert, Les romains chrétiens face à l'histoire de Rome. Histoire, christianisme et romanités en Occident dans l'Antiquité tardive (IIIe-Ve siècles) (Études Augustiniennes, París 1996) 6-7. Para una aproximación a los escritores latinocristianos de los siglos V y VI se puede consultar: J. Fontaine, La littérature latine chrétienne (Presses universitaires de France, París 1970); P. DE Labriolle, Histoire de la littérature latine chrétienne (Les belles lettres, París 1924); U. Moricca, Storia de la letteratura..., 1934.

8 El tema de la tipología cristiana puede ser abordado, por ejemplo, en J. DANIÉLOU, "Qu'est-ce que la typologie?", en L'Ancien Testament et les chrétiens (Éditions du 
tensamente seguido por los escritores cristianos de los primeros siglos, ya que les permitió demostrar cómo la historia narrada en el Antiguo Testamento viene a ser una prefiguración de Cristo y forma un conjunto unitario con la historia de sus días. Esta cuestión tipológica ha sido abordada desde variadas perspectivas, principalmente desde los ámbitos de la exégesis bíblica y de la filología clásica. Sin embargo, tal como lo proponen estudios históricos de la línea de Inglebert o del propio Marrou, la tipología cristiana resulta también una inconmensurable cantera para el trabajo del historiador, ya que en ella se representan las imágenes de los diversos modelos de una época.

Teniendo en cuenta que los hombres de los siglos V y VI no tenían en su horizonte un relato más importante que el de las Sagradas Escrituras, la tipología significó la posibilidad de acercamiento y estudio pormenorizado de las principales características que vislumbrarían en los libros del Antiguo Testamento, la persona de Jesucristo y de los sacramentos, de modo particular el bautismo. En esta misma línea cabría mencionar que ya desde el siglo II se había sustentado la idea de la antigüedad de la sabiduría judeo-cristiana en relación con la sabiduría pagana, habiéndose propuesto a Moisés como el gran profeta, historiador y poeta del mundo judío (Justino, Taciano y Clemente de Alejandría, por ejemplo) ${ }^{9}$. Por tanto, la historia -también entendida en un sentido apologético y pastoral- y el uso de esta dentro de la literatura cristiana se anclaría en la herencia clásica y patrística, así como en la preservación de la tradición de lo antiguo y digno de ser recordado en tanto que manifestación de las mirabilia Dei ${ }^{10}$.

De este modo, y con el objetivo de presentar modelos de reconocimiento para la humanidad entera, la hagiografía adquiere un lugar preponderante dentro de la tradición literaria de los escritores cristianos ${ }^{11}$.

Cerf, París 1951); J. DaniéLou, Sacramentum futuri. Études sur les origines de la typologie biblique (Beauchesne, París 1950).

9 J. PépIn, "Le challenge Homère-Moïse aux premiers siècles chrétiens", en Revue des sciences religieuses 29 (1955) 105-122.

10 Sobre el tema de la historia en el mundo monástico, véase J. Leclerce, L'amour des lettres et le désir de Dieu. Initiation aux auteurs monastiques du Moyen Âge (Éditions su Cerf, París 2011) 145-160.

11 Cf. C. Leonardi, "I modelli dell'agiografia latina dall'epoca antica al Medioevo", en Passaggio dal mondo antico al Medio Evo: da Teodorico a S. Gregorio Magno (Atti dei convegni Lincei, 45) (Accademia Naz. Dei Lincei, Roma 1980). 
Si bien la presentación de modelos de virtud redundaba de manera inmediata en la presentación de un exemplum por medio de los grandes santos de la época, así también los personajes del Antiguo Testamento son retomados en una clave cristocéntrica ${ }^{12}$, pues la historia aparecida en la Biblia, presentada como la acción de Dios en el devenir de su pueblo, adquirió una valoración como testimonio de la historia de la humanidad en su conjunto ${ }^{13}$.

De SPIRITALIS HISTORIAE GESTIS DE Avito DE Vienne: EL IDEAL DEL HOMBre JUSTO

Avito fue obispo de la ciudad de Vienne, en el valle del Ródano, entre los años 490 y 518. Destaca por su alto nivel cultural y su elevado conocimiento del latín ${ }^{14}$, lo que incluso determinó que la lectura de su obra formara parte del canon escolástico y su autor fuera ampliamente conocido en el mundo medieval ${ }^{15}$. Un conjunto de cartas de alto nivel intelectual dan cuenta del trabajo de este obispo en favor de la doctrina católica y en contra del arrianismo profesado por el reino burgundio ${ }^{16}$.

En torno al año 500 habría escrito su Historia espiritual (De spiritalis historiae gestis), una narración poética que está constituida por un conjunto de cinco libros que recorren la historia del mundo desde su creación hasta la salida de los judíos desde Egipto, todo en un sentido

12 J. DAniÉlou, "Qu'est-ce que...", 201. Cristo aparece como el Nuevo Adán, el verdadero Noé y el segundo Moisés.

13 E. Sánchez Salor, Historiografía latino-cristiana. Principios, contenido, forma (L'Erma di Bretschneider, Roma 2006) 132-136.

14 H. Goelzer, Le latin de saint Avit (F. Alcan Éditeur, París 1909) 3-11.

15 D. Shanzer - I. Wood, Avitus of Vienne: Letters and Selected Prose (Liverpool University Press, Liverpool 2002) 13.

16 La lucha de Avito contra la herejía arriana en el reino burgundio ha sido recientemente estudiada en: U. HeIL, Avitus von Vienne und die Homöische Kirche der Burgunder (De Gruyter, Berlín 2011); L. Pietri, "Les lettres d'Avit de Vienne. La correspondance d'un évêque politique", en Correspondances. Documents pour l'histoire de l'Antiquité tardive (Maison de l'Orient et de la Méditerranée, Lyon 2009) 311-331. También pueden consultarse D. J. Nodes, "Avitus of Vienne's Spiritual History and the Semipelagian Controversy. The Doctrinal Implications of Books I-III", en Vigiliae Christianae 38 (1984); M. REydellet, La royauté dans la littérature latine: de Sidoine Apollinaire à Isidore de Séville (École Française de Rome, Roma 1981) 87-137. 
poético y bajo el esquema de una historia universal ${ }^{17}$. El De spiritalis recuerda el inicio del mundo, el pecado original, la sentencia de Dios, el diluvio universal y el paso por el mar Rojo. Si bien la estructura se da en forma de cantos, esta conserva el concepto clásico de una epopeya y, por tanto, narra acontecimientos con un criterio pedagógico y con un claro interés por la exaltación de las virtudes de los patriarcas (Abraham, Noé y Moisés, por ejemplo $)^{18}$.

En cuanto a su escritura, nuestro autor galo-romano no demuestra una preocupación especial por la exégesis bíblica, sino más bien por la interpretación alegórica de los textos de la Sagrada Escritura ${ }^{19}$, llegando, incluso, hasta la dramatización misma de los acontecimientos ${ }^{20}$. No obstante, los modelos presentados como "hombres justos" u "hombres virtuosos" permiten observar la preocupación del autor por su labor moralizadora, ya que estas figuras serían una prefiguración y exaltación de la persona de Cristo, y se presentarían como testigos de la acción de la Providencia divina en el desarrollo de la historia del mundo.

En el poema de Avito destaca una labor de difusión de la Palabra de Dios, casi en un sentido inspirado. La historia bíblica propuesta por el autor deja de manifiesto ciertas libertades de orden cronológico, ya que sus lectores habrían sido principalmente personas instruidas en la fe, con un conocimiento del mensaje cristiano. Así, la obra puede llegar a ser

17 Véase: M. Roberts, "Rethoric and Poetic Imitation in Avitus' Account of the Crossing of the Red Sea ('De Spiritalis Historiae gestis' 5.371-702)", en Traditio 39 (1983). Para el caso del prólogo, véase: M. Roberts, “The prologue to Avitus 'De Spiritalis Historiae Gestis': Christian Poetry and Poetic License", en Traditio 36 (1980).

18 En la actualidad, los principales aspectos de la poesía épica de Avito han sido recogidos en la edición crítica editada por la colección Sources Chrétiennes: AvIT DE Vienne, Histoire Spirituelle, vols. Iy II, N. Hecquet-Noti (ed.) (Éditions du Cerf, París 1999 y 2005). Para el texto latino hemos seguido esta edición.

19 F. Stella, Poesia e teologia. L'occidente latino tra IV e VIII secolo (Jaca Book, Milán 2001) 129-137; M. Simonetti, La produzione letteraria latina fra romani e barbari (sec. V-VIII) (Institutum Patristicum Augustinianum, Roma 1986) 127-131.

20 La caída de Adán ha sido estudiada, desde un ámbito más bien filológico, en tanto que paráfrasis y diálogo dramático. Sin embargo, resulta de interés la lectura del texto a partir de la idea de la responsabilidad adánica y la toma de conciencia del significado del primer pecado. Véase: P.-A. Deproost, "La mise en scène d'un drame intérieur dans le poème sur le péché originel d'Avit de Vienne", en Traditio 51 (1996) 70-73. 
considerada como una "epopeya bíblica" ${ }^{21}$ plasmada en el esquema de la historia de la salvación, pues los cantos no dan cuenta solo de la caída del ser humano, sino que también presentan a Dios como protagonista de la historia, protagonismo que cambia a partir de la desobediencia adánica producto del pecado. Es por esto que, al mismo tiempo, existe una permanente reminiscencia de la condición paradisíaca anterior al pecado original, condición que en cierta forma aparece como necesaria para aquel que busca la justicia y la rectitud en la historia: "al que es justo le resulta fácil obedecer" 22 . Por su parte el diablo, antagonista del hombre desde el inicio del mundo, se gozaría en la participación de este en su infelicidad a través de la corrupción en la historia: "he aquí la única consolación que permanece en mi degradación: si no puedo subir a los cielos nuevos que me han sido cerrados, que estos se cierren también para los hombres"23.

Ahora bien, si toda la obra de este autor gira en torno al modelo implícito de Cristo en el relato veterotestamentario ${ }^{24}$, al mismo tiempo esta se puede llegar a constituir en un referente doctrinal que asegura la ortodoxia de Avito. En este sentido, el De spiritalis se puede situar dentro de una tradición histórico-teológico-literaria propia del pensamiento cristiano, y puede compararse, por ejemplo, con el Tractatus mysteriorum de Hilario de Poitiers o con el De gubernatione Dei de Salviano de Marsella, obras que no son propiamente historiográficas, pero que resultan muy importantes para el estudio de los arquetipos históricos de una determinada sociedad -en este caso, la sociedad cristiana de la Europa tardo-antigua-. Hilario, por ejemplo, hace un recorrido por la historia del Antiguo Testamento, y Salviano, a su vez, presenta la acción de la Providencia en los acontecimientos del mundo, proponiendo el modelo del hombre humilde y piadoso como el modelo del verdadero cristiano, pues en la piedad se manifestaría el reconocimiento de la grandeza divina. Al respecto Avito escribe: "recibe, Tú que no quieres que se

21 N. Hecquet-Noti, "Introduction", en Histoire Spirituelle (Éditions du Cerf, París 1999) 38-51. Para lo relacionado con el público de la obra y su proyecto de creación, véanse las páginas 33-37.

22 De spiritalis, I, 318: facilis custodia recti est.

23 De spiritalis, II, 107-109: haec mihi deiecto tantum solacia restant. Si nequeo clausos iterum conscendere caelos, his quoque claudantur.

24 Cf. N. Hecquet-Noti, "Introduction”, 40-45. Particularmente interesantes resultan sus observaciones con relación a la figura de Cristo y a la tipología. 
multipliquen las razones para morir, a los corazones que gimen y que te confiesan a Ti" 25 .

La historia humana, en el sentido cristiano transmitido por el obispo de Vienne, se reduciría a dos grandes etapas que abarcan dentro de sí la totalidad del tiempo vivido por el hombre: la caída de Adán y la salvación llevada a cabo con el sacrifico redentor de Cristo, y que se prolonga hasta su Parusía. Sin embargo, a lo largo de todo el poema no es posible apreciar un desarrollo explícito de la segunda venida, sino más bien una prefiguración a partir de la tipología bíblica que, como hemos mencionado, es característica de la literatura patrística de los primeros siglos. En el De spiritalis se volvería a repetir, entonces, la dinámica propia de la teología de la historia, dinámica que se podría llegar a entender a partir de la "relación" entre el pecado del hombre y la gracia salvífica. Recién comenzado el texto, y poniendo en evidencia su proyecto literario y la profundidad de su "poesía de la introspección" 26 , el poeta plasma la responsabilidad de Adán en el pecado original y su culpabilidad como causa de todas las calamidades de la humanidad y de la historia ${ }^{27}$ : "tú, primer padre, que por la semilla de la muerte privaste a la posteridad caída del germen de la vida” ${ }^{28}$.

El autor se toma la libertad de poder escribir de manera alegórica los acontecimientos bíblicos, con el fin de poder llevar a buen término su objetivo religioso-moralizador y, además, estético ${ }^{29}$. Esta misma libertad propiciada por la creación literaria le posibilita la elección de los sucesos del Antiguo Testamento, así como la forma de su exposición, lo que se encuentra en relación directa con lo que él quiere mostrar como

25 De spiritalis, III, 407-408: suscipe, qui non uis moriendi crescere causas, quos confessa tibi gemitus pia pectora fundunt.

26 J. Fontaine, Naissance de la poésie dans l'Occident chrétien. Esquisse d'une histoire de la poésie latine chrétienne du IIIe au VIe siècle (Études Augustiniennes, París 1981) 258.

27 F. Capponi hace notar la carencia de una conceptualización sobre el pecado que se halla en la poesía de Avito. Sin embargo, esto podría ser mejor explicado a partir de la proposición de Stella en cuanto a la culpa como motor de la obra del Poeta. Véase: F. Capponi, "I limiti didascalici nella poesia di A. E. Avito", en Latomus 26 (1967) 158-160; F. Stella, Poesia e teologia..., 129-137.

28 De spiritalis, I, 7-8: qui semine mortis tollis succiduae uitalia germina proli.

29 A. Roncononi, "La epica biblica di Avito di Vienne", en Vetera Christianorum 9 (1972) 305-306. 
representaciones edificantes para los hombres de su tiempo ${ }^{30}$. Al no ser una obra de especulación teológica, el De spiritalis logra concretar un esfuerzo por crear lo que ha sido llamado "un vocabulario de la teología poética" ${ }^{31}$, el que si bien no es preciso, le servirá para la descripción de los acontecimientos propios de las Sagradas Escrituras y, más importante aún, será heredado por el mundo medieval.

Avito propone una enseñanza moral a través de la figura de Noé, quien es presentado como el hombre virtuoso que se encuentra en contraposición a los hombres viciosos de sus días, los que se burlaban de él despreciándolo: "ya en ese momento las pasiones habían dividido a los hombres, del mismo modo como hoy se comporta la humanidad" 32 . Esta conducta de desprecio hacia el justo se materializa en algunos pasajes que serían una suerte de exhortación u homilía, tal como lo ha notado N. Hecquet-Noti ${ }^{33}$. El objetivo de Avito sería claro: la propuesta de un paralelo evidente entre la corrupción de los hombres antiguos y la situación de los hombres de sus días, resultando ser una exhortación universal dirigida a los cristianos de inicios del siglo VI: "pero los hombres, que presienten los riegos de un peligro cierto, asimismo, no han tenido temor de la muerte inminente" 34 .

La gran diferencia de Noé con los otros hombres de su tiempo es la obediencia a Dios y la realización de la labor sagrada, es decir, los preceptos ordenados por Dios se ponen en práctica y contribuyen a la realización de un nuevo orden, a pesar de la debilidad humana: "apoya nuestros esfuerzos con tu ayuda a fin de que nuestra débil mano tenga la fuerza para construir algo tan grande" 35 . Esta actitud viene a ser, entonces, una suerte de contemplación del orden creado, así como un signo

30 Aunque los escritos de Avito no corresponden a una obra teológico-histórica, parece ser que la preocupación por su tiempo y la reflexión sobre este fueron hechos con destacada objetividad. Cf. U. HeIL, Avitus von Vienne..., 35.

31 F. Stella, Poesia e teologia..., 132.

32 De spiritalis, IV, 318-319: haut aliter studium iam tunc diuiserat omnes, quam nunc mundus habet.

33 Véase el comentario de N. Hecquet-Noti (ed.), Avit de Vienne. Histoire Spirituelle, vol. II (Éditions du Cerf, París 2005) 72-73, nota al pie nº 1 .

34 De spiritalis, IV, 352-353: ast homines, quos sors certi discriminis urget, uicina nec morte pauent.

35 De spiritalis, IV, 291-292: auxiliumque tuum conatibus insere nostris, ut tenuis tantam ualeat manus edere molem. 
de la virtud del santo, y en esta característica radicaría, por tanto, una de las principales tareas del autor: el deseo de instruir y divulgar la verdad a través de la moralización de sus contemporáneos con el fin de encontrar la interioridad plena; en otras palabras, "la contemplación es la finalidad de todo esfuerzo moral"36.

Ahora bien, el lugar alcanzado por la santidad y la continuidad histórica impuesta por el desarrollo del texto ponen en evidencia el tópico de la vida interior y los milagros ${ }^{37}$. En otros términos, el ejercicio de la virtud hace posible que Noé lleve a cabo el mandato que le había sido prescrito por Dios, a pesar de su aparente incompetencia. La corrupción se manifiesta por la invasión incontrolable de los vicios, en oposición directa a la imagen de virtud del hombre justo. Si bien el uir Dei no se encuentra libre del pecado, su rechazo a él le permite su comprensión más profunda de la historia en cuanto lugar de manifestación de los portentos de Dios, pues quien conoce el mal ya se encuentra privado, en cierta forma, de la felicidad: "quien conoce el mal ya se encuentra privado, parcialmente, de su felicidad" 38 .

En el canto V, por ejemplo, se puede apreciar un desorden cronológico en relación con los acontecimientos narrados en el Génesis, desorden que se explica a partir de un recurso literario querido por el autor. Al momento de narrar la salida de Egipto y el paso por el mar Rojo, él pone el acento en las acciones milagrosas y en los prodigios divinos que manifiestan la acción de Dios en el tiempo humano ${ }^{39}$. Su deseo es el de cantar una oda al mundo incorrupto anterior al diluvio, ese mundo que se intenta recuperar con la figura de Moisés y que ya había sido presentado en la última parte del canto anterior (después del diluvio): "y así el hombre piadoso comprendió que el mundo estaba purificado" " ${ }^{\text {. Así, }}$ su relato recomienza la historia en cada canto, y transmite a través de

36 C. Dagens, Saint Grégoire le Grand. Culture et expérience chrétiennes (Études Augustiniennes, París 1977) 257; Cf. F. CApponi, "I limiti didascalici...”, 160.

37 A modo de introducción a la relación milagro-historia, véase: M. ModicA, "Il miracolo come oggeto di indagine storica”, en Miracoli. Dai Segni alla storia (Viella, Roma 2000).

De spiritalis, II, 379-380: caruit iam parte bonorum qui mala cognouit.

P.-A. Deproost, "La mise en œuvre du merveilleux épique dans le poème De Diluuio Mundi d'Avit de Vienne", en Jahrbuch für Antike und Christentum 34 (1991) 103.

40 De spiritalis, IV, 584-585: simplex indicio purumque pius sic comperit orbem. 
la libertad de la poesía lo que él consideraría la maravilla del tiempo de Cristo, que hace nuevas todas las cosas ${ }^{41}$.

En consecuencia, la figura de Moisés, el "héroe legislador"², se configura a partir del modelo de profeta, y Avito lo propone como modelo de virtud en el culto y en la vida litúrgica. En otras palabras, su obediencia se pone a prueba y gana el favor de Dios pues es modelo de piedad y de respeto por los ritos ${ }^{43}$ : "el Creador le da sus instrucciones a propósito de los cultos, y le muestra, igualmente, cómo la Víctima mística da sentido al culto solemne" ${ }^{44}$. Por consiguiente, Avito logra presentar cómo el verdadero cristiano es el hombre que a partir de la comprensión del misterio divino vive en permanente contacto con lo sobrenatural, casi en un sentido teológico y de peregrinación en la realidad cotidiana. Es por esto que podemos afirmar que las particularidades del canto $\mathrm{V}$ se encontrarían enraizadas, más bien, "en una moral cristiana presentada bajo imágenes bíblicas” ${ }^{3}$.

\section{Los Dialogi del papa Gregorio I y los hombres del Siglo VI}

Gregorio Magno nació dentro de la familia patricia de los Anicios, alrededor del 540, y no cabe duda de que su educación fue la propia de un miembro de la élite romana. Fue senador y prefecto de Roma en torno al año 573, y experimentó de modo presencial gran parte de los desafortunados acontecimientos del siglo VI. En dicha ciudad, creó un monasterio y fue elegido Papa en $590^{46}$. Si bien el conjunto de su obra es amplísimo, hemos optado por centrarnos en los cuatro libros de los Diálogos (Dialogi), obra en la que se relata una serie de vidas ejemplares

41 Apc. 21, 5.

42 De spiritalis, V, 67: legifer heros.

43 N. Hecquet-Noti (ed.), Histoire Spirituelle, vol. II, 174, nota 1.

44 De spiritalis, V, 221-222: instruit hos sacris simul informatque Creator, mystica sollemnem quo pandat uictima ritum.

45 J. DANiÉLOU, Sacramentum futuri..., 48.

46 Como estudio histórico-biográfico, véase: R. A. Markus, Gregory the Great and his World (Cambridge University Press, Cambridge 1997); S. Boesch Gajano, Grégoire le Grand: aux origines du Moyen Âge (Éditions du Cerf, París 2007). 
que manifiestan los principales aspectos de la teología de la historia que, a nuestro juicio, subyacen en el fondo del relato ${ }^{47}$.

Su obra, enmarcada dentro del ámbito de la hagiografía, no se podría llegar a entender si antes no hay un deseo por parte del lector moderno de acercarse al trasfondo teológico que da vida al relato, y que es el que permite que el autor lleve a cabo su labor pedagógica a través de la presentación de diversos modelos de hombres justos. En ese sentido, las palabras de U. Moricca resultan particularmente iluminadoras: "la hagiografía reúne en sí las características y fines de la poesía, de la teología de la filosofía y de la historia” ${ }^{38}$.

En efecto, resulta necesario recordar que para el pensamiento cristiano, incluido el pensamiento histórico, los relatos hagiográficos cumplen un rol decisivo en relación con la Providencia divina. No se trata solo de un género historiográfico más, sino que ellos dan lugar a la construcción de un discurso particular, enraizado en un sentido escatológico que da vida al texto. El relato biográfico de un determinado personaje es digno de ser contado porque él servirá para la edificación de la audiencia, en un sentido moral, tal como lo afirma H. de Lubac: "la historia era, pues, una ciencia moral, que se estudiaba en vista de mejorar las costumbres" 49 . Entonces, el relato hagiográfico en cuanto biografía podría entenderse como una fuente histórica de primer orden, ya que transmite "la cristalización literaria de las percepciones de una conciencia colectiva fijada

J. M. DE la Torre, Literatura cristiana antigua, entornos y contenidos. Desde las postrimerías del Imperio romano de Occidente hasta los albores de la 'oscura Edad Media latina', vol. V (Ediciones Monte Casino, Zamora 2009) 345.

48 U. Moricca, Storia della letteratura..., 1677. La cuestión de la hagiografía ha sido difusamente tratada. Para remitirse a la labor hagiográfica de Gregorio en sus Dialogi, se sugiere consultar el completísimo estudio de: S. Boesch Gajano, Grégoire le Grand hagiographe. Les Dialogues (Éditions du Cerf, París 2008). Junto a ello, podemos mencionar, entre otros: S. Boesch Gajano, "La proposta agiografica dei Dialogi di Gregorio Magno”, en Quaderni Medievali 21 (1980); S. Boesch Gajano, "Dalla storiografia alla storia”, en Miracoli. Dai segni alla storia (Viella, Roma 2000); M. Heinzelmann, "Studia sanctorum. Éducation, milieux d'instruction et valeurs éducatives dans l'hagiographie en Gaule jusqu'à la fin de l'époque merovingienne", en Haut Moyen-âge: culture, éducation et société (Publidix, Nanterre 1990). También se puede consultar: Hagiographie, cultures et sociétés: IVeXIIe siècles (Études Augustiniennes, París 1981).

49 H. DE Lubac, Exégèse médiévale. Les quatre sens de l'Écriture, vol. II (Aubier, París 1959) 467. 
definitivamente en el texto" ${ }^{\text {}}$. La tarea del escritor cristiano, en consecuencia, se asienta en la historia porque esta da testimonio de la acción providente de Dios en el mundo, y de modo excelso a través de los santos, quienes son ejemplo para el futuro ${ }^{51}$. Es por esto que Moricca ha llegado a afirmar que en el siglo VI este género era uno de los géneros literarios más cultivados ${ }^{52}$. Así, el historiador tiene obligación de revisar los textos patrísticos para reconstruir, con cierta aproximación, el modo de pensar de los primeros siglos cristianos ${ }^{53}$.

Introducirse en la obra del romano Gregorio supone también una introducción en los acontecimientos históricos que ordenan su cosmovisión, es decir, una sociedad en crisis que busca garantes de la continuidad romana, de la legitimidad del poder y, en definitiva, de la relación de lo terrenal con lo sobrenatural. Es por esto que el estudio de los Dialogi supone un acercamiento privilegiado al estudio del pensamiento y de las formas mentales que dan lugar a lo que conocemos como el Occidente alto medieval ${ }^{54}$. Quizás por eso se podría explicar su gran difusión y la significativa presencia de manuscritos en bibliotecas de monasterios a lo largo de toda Europa.

50 E. SÁnchez Salor, Historiografía..., 28-29. Véase también: P. J. Galán (ed.), Vida de san Benito y otras historias de santos y demonios. Diálogos. Gregorio Magno (Trotta, Madrid 2010) 15: "no puede perderse de vista, en efecto, que para los autores cristianos, especialmente de los primeros siglos, hagiografía e historiografía se confunden inextricablemente".

51 E. Sánchez Salor, Historiografía..., 28-29.

52 U. Moricca, "Prefazione", en Gregorii Magni Dialogi. Libri IV (Istituto Storico Italiano, Roma 1924) XV.

53 A. DE VogüÉ, "Martyrium in occulto: le martyre du temps de paix chez Grégoire le Grand, Isidore de Séville et Valerius du Bierzo”, en Fructus centesimus. Mélanges offerts à Gérard J. M. Bartelink à l'ocasión de son soixante-cinquième anniversaire (In abbatia S. Petri, Steenbrugis 1989) 140.

54 U. Moricca, "Prefazione", LXIV-LXX. Con relación a la mentalidad de los hombres del siglo VI y la dinámica entre creencia y razonamiento, se puede consultar: $\mathrm{M}$. van Uytfanghe, "Scepticisme doctrinal au seuil du Moyen Âge? Les objections du Diacre Pierre dans les Dialogues de Grégoire le Grand", en Grégoire le Grand. Chantilly, Centre culturel Les Fontaines, 15-19 Septembre 1982. Actes (Éditions du CNRS, París 1986) 315-326. Este artículo propone la estructura narrativa de los Dialogi como una herramienta de gran utilidad para la comprensión de la religiosidad de los hombres del período estudiado. 
Ahora bien, este conjunto de relatos hagiográficos tiene como objetivo principal la narración de la vida y de los milagros de una serie de santos de la península itálica. Estructurado en cuatro libros, el segundo está dedicado íntegramente a la vida de san Benito, y el cuarto viene a ser un compendio sobre la muerte y la vida sobrenatural. Si bien los relatos pueden llamar la atención del lector moderno por su carácter maravilloso, son una muestra clara de la cosmovisión de una época de transición de un tiempo a otro ${ }^{55}$, así como de las tradiciones más profundamente arraigadas en el pueblo. En otras palabras, Gregorio se encuentra frente a una sociedad nueva, y su motivación para escribir no son los cánones clásicos (a diferencia de Avito), sino, más bien, la formación espiritual y el deseo de preservar la supremacía de la "ciencia sagrada" 56.

Sin embargo, un tema a considerar es la íntima relación de los Dialogi con todo el pensamiento gregoriano en su conjunto ${ }^{57}$. Tanto $S$. Boesch Gajano como A. de Vogüé han contribuido sobremanera a la correcta valoración de esta obra en su contexto general. La primera ha demostrado la relación indisoluble entre las labores intelectual y pastoral de nuestro autor, hecho que se encuentra sustentado en la amplia literatura teológica de Gregorio, y que tiene como principal característica "la memoria histórica y la admonición espiritual" ${ }^{8}$. El segundo, por su parte, ha presentado -entre otros muchos aspectos- la cuestión sobre el sentido "popular" y el auditorio al que están dirigidos los Dialogi. Después de afirmar que los lectores serían, más bien, un público instruido, él ha hecho hincapié en la dificultad para poder distinguir la forma de escribir de esta obra en relación con el resto de sus escritos, entendiéndola en su trasfondo pedagógico y moral. Esto último confirmaría, tal vez, la posibilidad de diferentes receptores y estadios de lectura del texto ${ }^{59}$.

55 C. Dagens, "L'Église universelle et le monde oriental chez saint Grégoire le Grand", en Istina 20 (1975) 474.

56 Véase: C. Dagens, "Grégoire le Grand et la culture: de la sapientia huius mundi à la docta ignorantia”, en Revue des Études Augustiniennes 14 (1968) 17-18.

57 C. Dagens, Saint Grégoire le Grand..., 233.

58 S. Boesch Gajano, Grégoire le Grand hagiographe..., 42.

59 A. DE VogüÉ, "Introduction”, en Grégoire le Grand. Dialogues, vol. I (Éditions du Cerf, París 1978) 44-45, 80. La cuestión sobre el público de los Dialogi ha sido nuevamente tratada por S. Boesch Gajano, quien es partidaria de la existencia de diferentes niveles de lectura de la obra. Para ella, así como para C. Dagens, el texto está pensado y escrito para distintos tipos de lectores. Véase también: G. Cremas- 
Retomando la pregunta sobre el estudio de los arquetipos humanos, estos responderían a una búsqueda por la excelencia humana y por la práctica heroica de las virtudes, tanto en su dimensión cardinal como teologal. Así, la dinámica del pecado, del heroísmo y de la gracia ${ }^{60}$, clave para la comprensión de la vida humana, posibilitaría la explicación de la tipología del hombre "justo", el cual se representará de manera excelente en hombres como Benito de Nursia, quien es entendido por Gregorio como: "mártir de la paz, héroe de la caridad, de la castidad y de la fe"

La orientación de la obra se encamina no solo a una mera descripción de los acontecimientos, sino más bien hacia una dimensión teleológica propia de la concepción histórica del cristianismo. A partir de la apreciada edición redactada por U. Moricca en 1924, los estudios sobre nuestro autor latino han obtenido una renovación considerable. A este respecto, el acercamiento a una lectura que conciba la obra de Gregorio como un mero relato de acontecimientos maravillosos resultaría un tanto anacrónico $^{62}$, pues, a nuestro juicio, los elementos propios de una concepción de la historia en su sentido providencial se encontrarían claramente esbozados. Además, en los Dialogi es posible encontrar la concreción del que será el futuro método medieval, es decir, la narración de los datos y de los acontecimientos históricos encauzados hacia una dimensión sobrenatural. Los milagros, por tanto, aparecerían con el fin de ilustrar la doctrina, y no como modelos literales de conducta cristiana ${ }^{63}$ : "los débiles deben venerarlos, no imitarlos"64. En este sentido, se podría llegar a

COLI, "Infirmantium persona (Gregorii Magni Dialogi 4, 4, 9). Sui dubbi del diacono Pietro", en Gregorio Magno. Esegeta e pastore d'anime (Centro italiano di studi sull'alto Medioevo, Spoleto 2012) 65.

Cf. G. Freyburger - L. Pernot (eds..), Du héros païen au saint chrétien (Études Augustiniennes, París 1997) 24.

61 U. Moricca, Storia della letteratura..., 1680-1681. Cf. G. Cremascoli, "I viri Dei dell'Umbria nei Dialogi di Gregorio Magno", en Gregorio Magno. Esegeta e pastore d'anime (Centro italiano di studi sull'alto Medioevo, Spoleto 2012) 112: "il secondo libro dei Dialogi può essere definito un vero trattato sulla santità".

62 El tema de lo maravilloso ha sido abundantemente trabajado. Sin embargo, hacemos referencia al señero trabajo de P. Boglioni, "Miracle et nature chez Grégoire le Grand", en Cahiers d'études médiévales 1 (1974).

63 Cf. W. F. Bolton, "The Supra-Historical Sense in the Dialogues of Gregory I", en Aevum 13 (1959) 209; C. Dagens, Saint Grégoire le Grand..., 230.

64 Dialogi, I, 1, 7: infirmis ueneranda sunt, non imitanda. Si bien hemos tenido acceso a la edición de Moricca, para la citación del texto latino hemos utilizado la edición 
decir que el relato de los Dialogi tendría como intención la generación de un movimiento anímico en el lector, movimiento que le invitaría a tomar en consideración el mundo invisible, le llamaría a la conversión y le llevaría a la contemplación ${ }^{65}$.

El acceso a esta dimensión sobrenatural se haría posible gracias a la tipología del milagro - utilizando el concepto de S. Boesch Gajano-, la que debería ser entendida a partir de la uirtus del santo y de la acción divina a través del acontecimiento portentoso, tanto con una función protectora como punitiva ${ }^{66}$. Empero, la motivación pedagógico-moral resultaría explícita, y se encontraría dentro del ámbito de la enseñanza de una teología bajo un marco histórico, es decir, "se hace comentando la historia bíblica" ${ }^{\circ}$. Asimismo, la valoración de la obra en su sentido histórico, y teniendo en cuenta sus intenciones alegóricas (que en ningún caso le restan valor ${ }^{68}$, permite ver que el héroe cristiano traspasa la temporalidad y forma parte de la "constelación de hombres justos" que no hacen otra cosa sino unirse orgánicamente en el universo de la historia salutis, siendo esta una única historia en conjunto con los relatos del Antiguo Testamento ${ }^{69}$. En el caso concreto de san Benito, por ejemplo: "con la

de Sources Chrétiennes: Grégoire le Grand, Dialogues, vols. II y III, A. De Vogüé P. Antin (eds.) (Éditions du Cerf, París 1979 y 1980).

65 Véase V. Recchia, "La compositio dei libri I e III dei Dialoghi di Gregorio Magno", en Invigilata lucernis 24 (2002) 194; C. DaGens, Saint Grégoire le Grand..., 231232; S. Boesch Gajano, "Dalla storiografia...”, 218.

66 S. Boesch Gajano, Grégoire le Grand hagiographe. Les Dialogues, op. cit., pp. 117-144.

67 M. Andrés, "Introducción general", en Obras de san Gregorio Magno. Regla pastoral. Homilías sobre la profecía de Ezequiel. Cuarenta homilías sobre los Evangelios (Biblioteca de Autores cristianos, Madrid 1958) 61. Para un estudio más acabado sobre el uso de la Biblia en la obra de Gregorio Magno, véase: R. Manselli, "Gregorio Magno e la Bibbia”, en La Bibbia nell'alto Medioevo (Centro italiano di studi sull'alto medioevo, Spoleto 1963); V. Recchia, "La visione di S. Benedetto e la compositio del secondo libro dei Dialoghi di Gregorio Magno", en Gregorio Magno. Papa ed esegeta biblico (Università di Bari, Bari 1996) 53: "Gregorio pensa e agisce biblicamente, cala la visione biblica nella storia. E, in questo, non soffre distrazioni o dispersioni”.

68 A. DE VogüÉ, “Grégoire le Grand et ses Dialogues d'après deux ouvrages récents", en Revue d'histoire ecclésiastique 83 (1988) 287.

69 Cf. G. Penco, "Le figure bibliche del vir Dei nell'agiografia monastica", en Benedictina 15 (1968) 2. 
luz de la contemplación interior se ensanchan los pliegues del alma, y su expansión en Dios es tal que ella se eleva por encima del mundo. Más aún, el alma del contemplativo se posa incluso sobre sí misma y, en la luz de Dios, se dilata interiormente" 70 , y más adelante agrega: "el alma del contemplador se dilató, arrebatada en Dios, y pudo ver sin dificultad todo lo que estaba debajo de Él [...], el espíritu del contemplador fue arrebatado hacia las alturas, y la Luz le mostró cuán pequeñas eran todas las cosas que se encontraban debajo" ${ }^{11}$.

Ahora bien, la idea de la conversión ${ }^{72}$ se encuentra presente a lo largo de toda la obra bajo la premisa de que la narración de los milagros no va orientada a una apología del personaje sino, más bien, a una defensa de la necesaria edificación de las almas. Entonces, los milagros contados con evocadores detalles no tienen otro objetivo más que el de llamar a la conversión de los hombres y a la admiración de los modelos de virtud como ejemplos de vida de $\mathrm{fe}^{73}$. De este modo, el criterio que estaría permeando toda la obra en cuestión apuntaría a un criterio de perfección cristiana en el que Cristo aparecería como el único gran modelo ${ }^{74}$. Los Dialogi vienen a ser, por tanto, la puerta a toda la tradición medieval que recuperó el modelo tipológico de los patriarcas ${ }^{75}$, y que los llevó a su presente histórico a través de la imagen de los santos que, aunque universales, también se tornaron regionales y aparecieron íntimamente unidos en la experiencia teológica que supone el carácter sagrado y el

70 Dialogi, II, 35, 6: quia ipsa luce uisionis intimae mentis laxatur sinus, tantumque expanditur in Deo, ut superior existat mundo. Fit uero ipsa uidentis anima etiam super semetipsam. Cumque in Dei lumine rapitur super se, in interioribus ampliatur.

71 Dialogi, II, 35, 7: uidentis animus dilatatus, qui, in Deo raptus, uidere sine difficultate potuit omne quod infra Deum est [...] quae uidentis animum quia ad superiora rapuit, ei quam angusta essent omnia inferiora monstrauit.

72 El término conuersio, frecuentemente presente en nuestros autores, se entiende como el paso de la increencia o del pecado a la fe y al arrepentimiento. Cf. C. DAgens, "La conversion de saint Grégoire le Grand", en Revue des Études Augustiniennes 15 (1969) 157.

73 M. Modica, "Il miracolo...", 23; S. Pricoco, "Introduzione", en Storie di santi e di diavoli. Dialoghi, vol. I (Mondadori, Roma 2005) XXXIII.

74 C. Dagens, "La conversion de saint Benoît selon saint Grégoire le Grand", en Rivista di storia e letteratura religiosa 5/2 (1969) 390-391; A. DE VOGÜÉ, "Introduction", 84.

75 Cf. J. STERn “Israël et l'Église dans l'exégèse de saint Grégoire le Grand”, en L'esegesi dei padri latini. Dalle origini a Gregorio Magno. XXVIII incontro di studiosi dell'antichità cristiana, vol. II (Institutum Patristicum Augustinianum, Roma 2000) 676. 
misterio de la historia. En este punto, la visión global de Gregorio resulta fundamental ${ }^{76}$.

Por consiguiente, el carácter heroico del hombre justo permite que haya una captación profunda de las verdades del cosmos y de la creación entera, captación que se conseguiría de manera más perfecta por medio de la contemplación de la realidad ${ }^{77}$. Asumiendo que el santo era, para el hombre del siglo VI, el amigo de Dios, y que la dinámica milagrovirtud se constituía en la característica que motivaba la explicitación de los signos divinos en el tiempo ${ }^{78}$, el mundo visible no sería otra cosa sino una imagen temporal de lo atemporal, una metáfora de lo invisible en la que la acción providente y milagrosa tendrían una plena cabida ${ }^{79}$. Se llegaría, incluso, a la presentación de la imagen profética del santo que adelanta los acontecimientos y que, de una u otra forma, llama a la conversión, a la virtud y a la penitencia ${ }^{80}$. De este modo, los Dialogi podrían ser entendidos como un "tríptico hagiográfico" elaborado en un cuadro escatológico, con san Benito ocupando un lugar central ${ }^{81}$.

76 P. Maymó i Capdevila, "Política de lo sacro y sacralización de la política según el epistolario de Gregorio Magno", en Correspondances. Documents pour l'histoire de l'Antiquité tardive (Maison de l'Orient et de la Méditerranée, Lyon 2009) 383; B. Luiselli, "Indirizzo universale e indirizzi nazionali nella storiografia latinocristiana dei secc. V-VIII", en La storiografia ecclesiastica nella tarda Antichità (Centro di studi umanistici, Messina 1980) 526-527; G. Cracco, "Tra gerarchie di Dio e gerarchie della storia: le avventure di un testo-chiave di Gregorio Magno”, en Rivista di Storia e Letteratura Religiosa 47/1 (2011) 9.

77 P. Courcelle, "La vision cosmique de saint Benoît", en Revue des Études Augustiniennes 13 (1967) 117. Courcelle hace un interesante paralelo entre autores paganos (Macrobio, Séneca, Cicerón, por ejemplo) y el libro II de los Diálogos, destacando particularmente la imagen de la ascensión celeste de san Benito. En cuanto a la idea de la contemplatio como virtud aprendida por el santo de Nursia, véase: J. H. Wansbrough, "St. Gregory's Intention in the Stories of St. Scholastica and St. Benedict”, en Revue Bénédictine 75 (1965) 147.

78 A. De Vogüé, "Introduction", 86; G. Cremascoli, "Il genus narrandi nei Dialogi di Gregorio Magno", en Gregorio Magno. Esegeta e pastore d'anime (Centro italiano di studi sull'alto Medioevo, Spoleto 2012) 127.

79 Cf. W. F. Bolton, “The Supra-Historical...”, 211.

80 C. Dagens, "La fin des temps et l'Église selon saint Grégoire le Grand", en Recherches de science religieuse 58 (1970) 284.

81 Véase A. DE VogüÉ, Saint Benoît. L’homme et l'œuvre (Abbaye de Bellefontaine, Bégrolles-en-Mauges 2001) 11. 


\section{El LUGAR DEL HOMBRE HUMILDE}

La humilitas vendría a ser, para Gregorio, la primera y mayor de las virtudes del héroe cristiano ${ }^{82}$. Solo a través de esta el hombre lograría conocer la sabiduría divina, que se constituiría en el verdadero saber de la humanidad, pues el santo: "en efecto, estima oportuno morir a los ojos de los soberbios, y resucitar a la vista de los humildes, a fin de que los primeros vean en él lo que deberían despreciar, y los segundos lo que deberían amar con total veneración" ${ }^{83}$. El alma cristiana se esclarecería y lograría ver más allá a través de la contemplación ${ }^{84}$, y su punto de partida se convertiría en su meta en tanto que visión de Dios. En este cuadro, la creación poética y la narración hagiográfica no harían otra cosa sino mostrar las maravillas divinas, casi como uerba divina, que iluminan y esclarecen la vida del hombre de fe.

Los humildes y despreciados son los testigos de la verdad ${ }^{85}$, y esta es la que les permite acceder al verdadero sentido de la historia humana, a la comprensión más profunda de que el devenir histórico sería, en definitiva, un acto de conversión y de reconocimiento de la necesidad de vivir como otro Cristo. Consecuentemente, el gran protagonista de los Dialogi sería, en palabras de G. Cracco, Dios mismo: "Gregorio Magno es consciente de componer con los Dialogi un nuevo Evangelio, una aretalogía ulterior donde, en el lugar del único protagonista, Cristo, también actuarían decenas de otros protagonistas" 86 . Igual afirmación puede ser hecha en relación con el De spiritalis de Avito, pues el sentido cristocéntrico de la obra se encuentra presente a lo largo del todo el poema, y en él no se logra apreciar más que una única prefiguración a partir de la

82 F. Tateo, "La struttura dei Dialoghi di Gregorio Magno", en Vetera Christianorum $2(1965) 127$.

83 Dialogi, II, 8, 9: ut coram superbis mori dignaretur, coram humilibus resurgere, quatenus et illi uiderent quod contemnerent, et isti quod uenerantes amare debuissent. En cuanto al tema del juicio y el infierno, véase G. Cremascoli, 'Novissima hominis' nei 'Dialogi' di Gregorio Magno (Pàtron, Bolonia 1979) 93-94.

84 J. LeclercQ, L'amour des lettres..., 38.

85 Cf. U. Moricca, "Prefazione”, LXIX: "Tra le virtù, le più pregiate, dopo la castità, sono l'umiltà e la modestia".

86 G. Cracco, "Tra gerarchie di Dio...", 9. 
tipología bíblica. Por tanto, no hay más que un único actor de la historia que se manifiesta a través de los patriarcas ${ }^{87}$.

El hombre justo logra un amplio conocimiento de sí mismo y de su participación en la obra salvífica a través de la interioridad que le proporciona la ascesis. En los Dialogi, por ejemplo, el conocimiento íntimo aparece reflejado de modo prístino con la figura de san Benito, quien de manera insigne, y superando toda posibilidad humana, mira el mundo a partir de una óptica atemporal: "el mundo entero, como concentrado bajo un solo rayo de sol, fue puesto ante sus ojos" ${ }^{88}$. Esta visión pondría en evidencia el conocimiento de las realidades del mundo alcanzado por el santo de Nursia a través de la contemplación, la que se constituye en una elevación del alma a la interioridad de Dios a través de un progreso moral y espiritual que rechaza el pecado y que se encuentra en el núcleo de la historia de la salvación ${ }^{89}$.

San Gregorio relata este espíritu de contemplación dando cuenta de la visión de san Benito y de la dilatatio de su espíritu a través de lo contemplado en un rayo de luz. Es de suponer, más allá del acontecimiento mismo, la profundidad del mensaje propuesto por el autor romano. Esta dilatación, que permitió a san Benito ver todo el mundo en un solo acto, se podría entender bajo la premisa de la comprensión total de la historia en un sentido profético al modo de los grandes profetas del Antiguo Testamento $^{90}$. En otras palabras, aparecería la dinámica del hombre que desde el tiempo logra ver la eternidad, acercándose a la comprensión, asimismo, de la temporalidad de lo humano. Por esto el protagonismo del santo sería un protagonismo fundado en un anonadamiento, ya que

87 Véase el comentario de N. Hecquet-Noti (ed), Avit de Vienne. Histoire Spirituelle, vol. I (Éditions du Cerf, París 1999) 254.

88 Dialogi, II, 35, 3: omnis etiam mundus, uelut sub uno solis radio collectus, ante oculos eius adductus est.

89 Cf. C. Dagens, Saint Grégoire le Grand..., 166 y 257; J. H. Wansbrough, "St. Gregory's Intention...”, 149-150. El autor señala cómo Gregorio habría tomado los modelos del profeta Daniel, de los Padres del Desierto y de los apóstoles Pedro y Pablo para ilustrar, de este modo, los ejemplos de renuncia, ascetismo y predicación, entre otros.

90 La lectura de la historia que hace Gregorio es, sin lugar a dudas, una lectura mística. Las virtudes de los patriarcas se actualizan en las virtudes de los santos. Cf. M. Reydellet, La royauté..., 490-492; V. Recchia, "La visione di S. Benedetto...”, 50. 
su verdadero papel en la historia se encontraría en el reconocimiento de su lugar dentro del plan salvífico divino ${ }^{91}$.

Esta comprensión, que se encuentra íntimamente unida a la compunción, permite profundizar en la relación de lo temporal y de lo eterno, cosmovisión propia de una sociedad como la de los siglos V y VI. En esta misma línea, las descripciones de Noé y Moisés hechas por Avito, por ejemplo, se podrían situar en esta dirección ya que ambos patriarcas habrían logrado una cercanía tan íntima con Dios que ellos podían conversar directamente con Él, acontecimiento que, en otras palabras, significaría la unión del tiempo y de la eternidad. San Benito y los otros monjes santos, por su parte, se constituirían en servidores simples y puros que no desearían otra cosa más que la unión con Dios ${ }^{92}$ pues: "por la pureza y sencillez de sus pensamientos, por una suerte de semejanza, ellos concuerdan ya con Él”’3.

\section{La PEDAGOGÍA DE LA HISTORIA}

Si continuamos en la dinámica de la teología de la historia, ¿el poema de Avito no querría constituir, de modo íntegro, todo un compendio único de la historia de la derrota del hombre por el pecado y del triunfo de este a través de la salvación de Cristo? Con todo, ¡̇la comprensión del mundo no se iluminaría a la luz de los acontecimientos narrados en el libro del Génesis? En este sentido, la figura de Moisés aparecería representando la cercanía y el conocimiento íntimo del corazón del pueblo de Israel y del querer de Dios, con quien hablaba cara a cara.

En efecto, el valor de la obediencia aparece constantemente mencionado en las obras en cuestión. La dinámica de la historia salutis se podría definir, en cierto modo, y siguiendo el poema de Avito y los relatos gregorianos, como la relación permanente entre la fidelidad a la voluntad de Dios, en contraposición a la desobediencia propia del pecado. Así, la oposición Providencia-obediencia versus desobediencia-envidia explicarían, en gran medida, la idea de la historia humana como un relato en

91 "La compunción es el medio para alcanzar la contemplación”: P. J. GALÁn (ed.), Gregorio Magno. Vida de san Benito..., 287, nota 198.

92 A. DE VogüÉ, Histoire littéraire du mouvement monastique dans l'Antiquité, vol. $X$ (Éditions du Cerf, París 2010) 183-184.

93 Dialogi, III, 15, 13: ipsa puritate ac simplicitate cogitationis quasi ex quadam iam similitudine concordant. 
el que la dinámica del pecado y la gracia estarían siempre presentes. Es por esto que el santo tendría poder sobre el diablo, gracias a la virtud que le permitiría oponerse a la envidia ${ }^{94}$. Por esta razón, entonces, los modelos propuestos por Gregorio se encarnarían en lo que P. J. Galán ha llamado: "las gestas milagrosas de los héroes cristiano" " Los milagros operarían solo como muestra de la acción de Dios en el mundo, por lo que se constituirían, en el fondo, en la intervención divina en la historia, y conllevarían una forma de significar propia de la pedagogía divina, la que utilizaría los prodigios y signa para dar una enseñanza y manifestar una virtud interior ${ }^{96}$.

Avito menciona, por ejemplo, que los ángeles alaban porque obedecen las órdenes de lo alto y, por tanto, su obediencia sería una obediencia angélica fundada en el conocimiento de Dios y en su alabanza: "hay en el cielo, en número mayor que un destacamento, un sinfín de coros de ángeles que por una alabanza eterna aclaman y celebran a Dios" ${ }^{\prime 7}$. Por otro lado, él advierte, en un sentido teológico, que el pecado del diablo es mayor que el de los hombres, por ser este una criatura angélica ${ }^{98}$. Por su parte, el hombre que es propuesto como modelo -tanto por Gregorio como por el obispo de Vienne- obedecería por amor, porque en el conocimiento divino de Dios el amor habría hecho posible que Noé obedeciera sin poder dejar de cumplir las órdenes celestes. El propio Benito, por su parte, habría huido del mundo para obedecer la voz interior y así buscar contemplar a Dios: "Benito amaba más sufrir los males del mundo antes que sus alabanzas, y padecer fatigas por los trabajos de Dios antes que ser ensalzado por los reconocimientos de esta vida" ${ }^{\prime 9}$.

\footnotetext{
94 S. Boesch Gajano, Grégoire le Grand hagiographe..., 174.

95 P. J. Galán (ed.), Gregorio Magno. Vida de san Benito..., 15.

96 Cf. G. R. Evans, The Thought of Gregory the Great (Cambridge University Press, Cambridge 1988) 14-15; C. Dagens, Saint Grégoire le Grand..., 230-231; S. Pricoco, "Introduzione", XXIX; G. Cremascoli, "Sul significato dei Dialogi di Gregorio Magno", en Gregorio Magno. Esegeta e pastore d'anime (Centro italiano di studi sull'alto Medioevo, Spoleto 2012) 382.

97 De spiritalis, IV, 190-192: est ille in caelis numero praestantior omni angelicus sine fine chorus, qui laude perenni conclamat celebratque Deum.

98 De spiritalis, II, 50-52: nam crimen acerbat auctor: in ignoto minor est peccante reatus, durius atque malum, quod maior fecit, habetur.

99 Dialogi, II, 1, 3: Benedictus, plus appetens mala mundi perpeti quam laudes, pro Deo laboribus fatigari quam uitae huius fauoribus extolli.
} 
Tentación y conocimiento de sí son dos aspectos fundamentales en las obras que hemos estudiado. Ante la pregunta del diácono Pedro, Gregorio recomienda tener miedo de las debilidades y esperanza en la acción divina: "conviene que nosotros tengamos confianza en la misericordia de Dios y, al mismo tiempo, temor de nuestra debilidad" 100 , imagen que recuerda la dada por Avito al referirse al diablo como el gran falsificador: "asimismo, un poder más grande aún le ha sido permitido, y él finge ser santo" ${ }^{101}$. Es por esto que el espíritu contemplativo, que se manifiesta en la verdadera virtud interior, es más importante que la realización de los milagros en tanto que gestos externos ${ }^{102}$. Esta búsqueda de la vida interior, entonces, se entiende como un dominio de sí y del mundo a través de actos heroicos ${ }^{103}$, pues los modelos propuestos por nuestros dos autores se constituyen en héroes y protagonistas de la historia porque, a través de la humildad, afrontan la tentación, resultan victoriosos y conocen la Verdad: "aquellos que se elevan con orgullo contra los preceptos de la Verdad, tendrán su cerviz aplastada en medio de los humildes"104.

Estaríamos, en consecuencia, frente a una idea de continuidad histórica característica del concepto de historia cristiana, y resultaría posible encontrar todo un relato histórico-salvífico que tiene características de universal, en donde los salui serían los verdaderos protagonistas de la historia humana ${ }^{105}$. Por consiguiente, podemos comprender que en Avito existe una concepción de su obra como un ciclo completo, el que comienza con Adán y su desobediencia a las órdenes divinas ${ }^{106}$. Como figuras opuestas al primer hombre, la purificación a partir de Noé y su obediencia a Dios permiten llevar a cabo la salvación de la humanidad, salvación que se proyectará con el pueblo de Israel que, de la mano de Moisés, atravesó el mar Rojo.

100 Dialogi, III, 7, 10: utique sic oportet et de Dei nos semper miseratione confidere, et de nostra infirmitate formidare.

101 De spiritalis, II, 73-74: maior adhuc etiam saeuo permissa potestas, ut sanctum fingat.

102 C. Dagens, Saint Grégoire le Grand..., 230-231.

103 A. DE VogüÉ, Histoire littéraire du mouvement monastique..., 151.

104 Dialogi, III, 12, 4: qui se superbe contra praecepta ueritatis eleuant, eorum ceruicem ueritas per humiles premat.

105 S. Boesch Gajano, Grégoire le Grand hagiographe..., 213-214.

106 En cuanto al tema de pecado original y la responsabilidad adánica, véase nota $n^{\circ} 20$. 
Por su parte, las palabras del libro II de los Diálogos exhortan al abandono de este mundo y a la búsqueda de la sabiduría verdadera, sabiduría que logra que el santo de Nursia sea presentado como "sabiamente ignorante y doctamente inculto" ${ }^{107}$. Esta característica propia del uir Dei sería la que haría fecunda la obra del cristiano, y la que le permite cumplir con la labor sagrada que le ha sido encargada ${ }^{108}$. Gregorio entiende la santidad, entonces, como la consecuencia directa de una vida llena de virtudes, tal como lo expresan sus palabras en relación con el presbítero Severo: "en efecto, el verdadero valor de la vida reside en la virtud de las obras, no en la ostentación de los milagros" ${ }^{109}$.

Ahora bien, si la dimensión escatológica viene a ser la dimensión predominante en las biografías propuestas por el autor romano, no puede dejarse de lado la dimensión tipológica expresada en la obra ${ }^{110}$. Tal como se ha indicado más arriba, los "justos" del Antiguo Testamento son reemplazados por los "santos" de los que tiene conocimiento nuestro autor romano ${ }^{111}$, y a través de ellos presenta las imágenes de la virtud y la heroicidad en esta vida. De este modo, en ellos aparece una concreción cristiana de la idea del héroe veterotestamentario, el que ahora se presenta como un modelo de hombre que interpela al lector y que le va mostrando el verdadero camino que lleva a la salvación ${ }^{112}$.

En definitiva, los fines pedagógico-morales de las obras de los obispos de Vienne y de Roma encontrarían un fundamento cristocéntrico a través del relato de los "héroes" (patriarcas y cristianos), quienes antes o después de la Encarnación, y de una manera tipológica, contribuirían con la restauración del orden primigenio por medio de la salvación. Por esta razón, el lugar del milagro y de la intervención de Dios en la historia humana ponen de manifiesto la confianza y la confortación en un

107 Dialogi, II, pról. 1: scienter nescius et sapienter indoctus.

108 Cf. De spiritalis, IV, 291-292.

109 Dialogi, I, 12, 4: uitae namque uera aestimatio in uirtute est operum, non in ostensione signorum.

110 W. F. Bolton, “The Supra-Historical...”, 208.

111 A. DE VoGÜÉ, "Introduction”, 124-126.

112 Véase C. Leonardi, "Modelli di santità tra secolo V e VII", Santi et demoni nell'alto Medioevo occidentale (secoli V-XI) (Centro italiano di studi sull'alto medioevo, Spoleto 1989) 261-283. 
período de incertidumbre, lo que redunda en una directa sintonía con la esperanza cristiana y con la rectitud de vida.

Por tanto, el ideal de perfección cristiana que se plasmará durante toda la Edad Media, encarnado de modo eximio en el ideal monástico, adquirió una dimensión alegórica nueva a través de las obras concebidas a la luz de los siglos V y VI. Si bien los modelos del Antiguo Testamento permanecieron como prototipos de vida cristiana, a la vez fueron renovados, principalmente a partir de san Gregorio y su descripción de san Benito y de los santos monjes de sus días. Estos fueron presentados, entonces, como ejemplos y testigos de las magnalia Dei, tal como también lo fueron los patriarcas y los profetas ${ }^{113}$.

113 G. Penco, "Le figure bibliche...”, 1-2; G. Cremascoli, "Sul significato dei Dialogi...”, 382-383. 
Resumen: La narración poética-teológica de Avito de Vienne y el conjunto de relatos hagiográficos de Gregorio Magno dan cuenta de la continuidad del ideal clásico de virtus y de su adopción por parte del cristianismo. La tipología bíblica basada en personajes del Antiguo Testamento, así como las vidas de santos occidentales contemporáneos a los autores, recrean un universo social y religioso propio del siglo VI. Asimismo, ponen de manifiesto el lugar de la historia como historia salutis y de la actuación de los hombres justos -los santos- en el devenir humano a través de su testimonio y de los milagros.

Palabras clave: Avito de Vienne, Gregorio Magno, virtud, milagros, santidad.

Abstract: The poetic-theological narrative of Avitus of Vienne and the set of hagiographic stories of Gregory the Great evidence the continuity of classical ideal of uirtus and its adoption by Christianity. The biblical typology based on characters of the Old Testament as well as the lives of Western Saints contemporary to the authors, recreate a social and religious universe distinctive of the sixth century. Also reveal the place of history as historia salutis and the role of just men -the Saints - in the human development through their testimony and miracles.

Keywords: Avitus of Vienne, Gregory the Great, virtue, miracles, holiness. 